Research Paper:

\title{
The Relationship Between Adolescents' Awareness of Non-alcoholic Fatty Liver and Their Health-Promoting Lifestyle
}

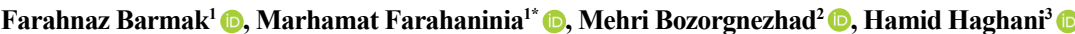

1. Department of Community Health Nursing, School of Nursing and Midwifery, Iran University of Medical Sciences and Health Services, Tehran, Iran 2. Department of Medical-Surgical Nursing, School of Nursing and Midwifery, Iran University of Medical Sciences, Tehran, Iran.

3. Department of Biostatistics, School of Public Health, Iran University of Medical Sciences, Tehran, Iran.

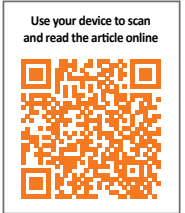

Citation: Barmak, F., et al. 2021. The Relationship Between Adolescents' Awareness of Non-alcoholic Fatty Liver and Their Health-Promoting Lifestyle. Journal of Client-Centered Nursing Care, 7(4), pp. 263-274. https://doi.org/10.32598/ JCCNC.7.4.93.19

https://doi.org/10.32598/JCCNC.7.4.93.19

Article info:

Received: 07 Jul 2021

Accepted: 02 Sep 2021

Published: 01 Nov 2021
Keywords:

Non-alcoholic fatty liver disease, Health promotion, Lifestyle, Awareness

\begin{abstract}
A B S T RA C T
Background: Lifestyle modification is recognized as the first step of fatty liver treatment. This study was done to determine the relationship between the awareness of the Non-Alcoholic Fatty Liver Disease (NAFLD) and adolescents' health-promoting lifestyle in senior high school students in the west of Tehran, Iran.

Methods: This descriptive-correlational study was performed on 338 high school students in 2020 . The students were recruited by cluster sampling method. The data were collected by demographic information form, awareness of non-alcoholic fatty liver questionnaire, and HealthPromoting Lifestyle Profile II (HPLPII) and were expressed using frequency, mean, standard deviation, and analyzed by inferential statistical tests of ANOVA, Chi-square, independent t-test, and Pearson correlation coefficient using SPSS 20.
\end{abstract}

Results: The results showed that the highest Mean \pm SD of health-promoting lifestyle was related to spiritual growth and self-actualization dimension (27.41 \pm 5.53$)$ and the lowest Mean \pm SD was related to the dimension of physical activity $(19.71 \pm 6.63)$. There was a significant relationship between awareness of NAFLD and the health responsibility subscale of HPLP ( $\mathrm{P}=0.004)$. Awareness of NAFLD had a direct relationship with the father's education ( $\mathrm{P}=0.004)$. The healthpromoting lifestyle was positively related to students' grade $(\mathrm{P}<0.001)$, birth order $(\mathrm{P}=0.019)$, economic status $(\mathrm{P}<0.001)$, number of children $(\mathrm{P}=0.037)$, and living with parents $(\mathrm{P}=0.031)$, and negatively associated with the students' age $(\mathrm{P}=0.014)$.

Conclusion: The significant relationship between knowledge about fatty liver and health responsibility indicates the need to increase students' awareness of this disease to improve a health-promoting lifestyle. Therefore, it is suggested that educational interventions be provided at different levels of prevention to empower students.

\section{* Corresponding Author:}

Marhamat Farahaninia, MSc.

Address: Department of Community Health Nursing, School of Nursing and Midwifery, Iran University of Medical Sciences and Health Services, Tehran, Iran Tel: +98 (21) 43651800

E-mail: farahaninia.m@iums.ac.ir 


\section{Highlights}

- Chronic diseases that pose a major threat to health, are often the result of poor lifestyle and cost the health care system dearly.

- Although adolescents and their health raise an extensively vital problem, studies on non-alcoholic fatty liver disease in adolescents have received little attention.

- The results of this study showed that the highest mean of health-promoting lifestyle was related to spiritual growth and self-actualization dimension and the lowest mean was related to the dimension of physical activity.

- There was a significant relationship between awareness of non-alcoholic fatty liver and the health responsibility of the students.

\section{Plain Language Summary}

Non-alcoholic fatty liver as one of the most prevalent chronic diseases is a silent and benign disease, which is preventable. It has been shown that improper lifestyle is responsible for most of the causes of chronic diseases and mortality. A health-promoting lifestyle is a process an individual pursues consciously to promote his/her health. This study discusses the relationship between awareness of non-alcoholic fatty liver disease and health-promoting lifestyle in secondary high school adolescents in the west of Tehran. The results showed that the spiritual growth and selfactualization dimensions of health-promoting lifestyle had the highest and the physical activity had the lowest score. Furthermore, the results revealed a significant relationship between awareness of the non-alcoholic fatty liver disease and health responsibility.

\section{Introduction}

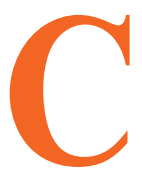

hronic diseases are the major threats to health and sources of healthcare costs (Riegel et al. 2018). Non-Alcoholic Fatty Liver Disease (NAFLD) is one of the most prevalent chronic diseases in developed and developing countries (Paknahad \& Zeraei-Bidgoli 2013; Shen et al. 2014; Zolfaghari et al. 2016); however, it is preventable (Ghevariya et al. 2014). Although the disease is silent and benign, it can lead to more advanced stages, like fibrosis, cirrhosis, liver transplant, and even death (Alavian 2012). The major established risk factors for NAFLD are obesity, insulin resistance, dyslipidemia (Perdomo, Frühbeck \& Perdomo 2019; Younossi 2019), an increase in calorie intake/poor diet, and lack of physical activity/exercise (Hallsworth, Avery \& Trenell 2016). The prevalence of NAFLD is $8-45 \%$ throughout the world (Perdomo, Frühbeck \& Perdomo 2019) while being reported at 27\% in Asia (Younossi et al. 2016). The incidence of this disease ranges from 2.9 to $7.1 \%$ in the general population of Iran (Lankarani et al. 2013), while it has been estimated at $27.88 \%$ among Iranian adolescents and children (Salehi Sahlabadi et al. 2018). The disease afflicts 20 out of 100000 individuals per year and the peak of the disease is in the $6^{\text {th }}$ decade of life and is more common in males (Tsuneto et al. 2010). The economic load linked to the NAFLD epidemic will be increasing since societies are gradually influenced by this global problem of general health (Allen et al. 2018). The economic load impacts of this disease approximate $\$ 103$ million in the USA and $\mathbb{C} 35$ billion in England, Germany, France, and Italy (Neuschwander-Tetri 2017). There is now no medicine for the treatment of this illness. Lifestyle modifications, such as dietary adjustments and increased physical activity, are the first treatment options (Chalasani et al. 2018; Vos et al. 2017).

The increasing prevalence of chronic diseases has led countries to pay more attention to related lifestyle behaviors because chronic diseases are the outcome of improper lifestyles (Baum \& Fisher 2014). Lifestyle is a unique pattern of characteristics, behaviors, and habits that each person shows. The World Health Organization defines lifestyle as specific and definable patterns of behavior that result from the interaction between personal characteristics, social relationships, environmental conditions, and socioeconomic status (Mohammadbeigi et al. 2016).

Statistics show that $70 \%$ of the diseases and $53 \%$ of mortality in the world are due to inappropriate lifestyles (Kalroozi et al. 2015). Health-promoting lifestyle as a 
process that is consciously performed by a person with the aim of promoting his/her health (Chuang et al. 2016), has a significant impact on reducing health costs, increasing people's life expectancy, and improving their quality of life (Kurnat-Thoma et al. 2017).

Lifestyle changes in the last decade have led to an increase in obesity in society as a whole and adolescents have been no exception (Salehisahlabadi et al. 2018). Studies have shown that adolescents, despite having the highest population incidence, have paid little attention to health care (Mohammadian et al. 2013). Lifestyle modification, with emphasis on proper eating habits and increased physical activity, can lead to weight loss and reduced fatty liver disease (Zou et al. 2018).

Eastern Mediterranean research also indicates the prevalence of non-communicable diseases in adolescents. Therefore, it is necessary for health care providers, education officials, and policymakers in this field to collect accurate information from adolescents about their health-related lifestyles to design and develop health promotion strategies (Molaeifard, Mohamadian, \& Haghighi Zadeh 2018).

Understanding adolescent health behaviors, especially their awareness of health-promoting behaviors is important for health-related interventions because their behaviors and decision-making processes are learned and sustained over time (Schnall, Okoniewski \& Tiase 2013).Studies on NAFLD in adolescents in South Asia have received little attention (Shaman et al. 2017), and most of the studies are from Western countries (Anderson et al. 2015).

Given the lifestyle changes, the lack of studies on the lifestyle of people with NAFLD, and the declining age of the prevalence of fatty liver, awareness of a health-promoting lifestyle can provide valuable information to improve adolescents' healthy lifestyles and assist in planning appropriate interventions to prevent chronic diseases, especially fatty liver. Therefore, this study was done to determine the relationship between awareness of NAFLD and health-promoting lifestyle among senior high school students of the west of Tehran in 2020.

\section{Materials and Methods}

It was a descriptive-correlational study. A total of 338 senior high school students of the west of Tehran were recruited by the cluster sampling method. To collect the data, the researchers referred to the General Education Administration of Tehran and received the permit for sampling from west of Tehran (education districts 2, 5 \& 6). Then, three public high schools for girls and three public high schools for boys were selected from each district (for controlling gender differences as confounding factors). In order to collect data, due to COVID- 19 and the impossibility of students attending schools, the questionnaires were first linked and this link was approved by the General Directorate of Education and the relevant regions. The researcher referred to the selected schools and after introducing himself and explaining the goals and importance of conducting the research, provided the link of the questionnaires to the school principal or deputy principal. Then, the questionnaires were sent to the students by the school officials through Telegram or WhatsApp groups.

The data were collected by three questionnaires. The first part of the questionnaire assessed basic demographic data. The second and third parts included general awareness of NAFLD and Health-Promoting Lifestyle Profile II (HPLP II).

The demographic questionnaire included the variables of educational level, age, gender, parents' employment, parents' education, birth order, economic status, height, weight, Body Mass Index (BMI), disease history, and residence conditions.

The public awareness questionnaire on NAFLD is a 14-item tool with three choices for each item as "correct", "incorrect" and "I do not know". The correct, incorrect, and I do not know answers are given a score of 1 , 0 , and 0 , respectively. The total score ranges from 0 to 14 and the total score for NAFLD is obtained by summing the number of correct answers. The higher the score, the higher awareness of NAFLD (Ghevariya et al. 2014). The validity and reliability of the Persian version of this questionnaire were first determined in this study. Three judges of the faculty members of the School of Nursing and Midwifery of Iran University of Medical Sciences evaluated this questionnaire to provide their views on its qualitative content validity. The questionnaire was revised after receiving their comments. To determine the reliability of this tool, the researchers used the KuderRichardson coefficient, which was estimated to be 0.73 .

The (HPLP II) has 52 items and six subscales, including spiritual growth (9 items), health responsibility (9 items), physical activity (8 items), nutrition ( 9 items), interpersonal relations (9 items), and stress management (8 items). The HPLP (II) is scored on a 4-point Likert scale (never $=1$, sometimes $=2$, often $=3$, and most of the time $=4$ ). The score of each subscale is the sum of the scores given to answers. The total score is obtained from the responses to 52 questions. The maximum and 
minimum scores of this scale are 208 and 52, respectively. Higher scores represent a better health-promoting lifestyle (Walker, Sechrist \& Pender 1987; Pender et al. 2015).

Mohammadi Zeidi, Pakpuor Hajiagha and Mohammadi Zeidi (2012) examined the validity and reliability of the Persian version of and estimated the Cronbach's alpha coefficient of 0.82 for the whole scale and 0.64-0.91 for the subscales. In the current study, Cronbach's alpha coefficient was calculated at 0.82 for the whole scale and 0.68-0.79 for the subscales. Data were described by frequency, mean, standard deviation, maximum, and minimum and were analyzed by the ANOVA, Chi-square, independent t-test, and Pearson correlation coefficient in SPSS 20.

\section{Results}

The students' age ranged from $15-18$ years $(16.7 \pm 0.96$ years) and most of them were males $(53.8 \%)$. Their average BMI was $23.17 \pm 4.54 \mathrm{~kg} / \mathrm{m}^{2}$. Also, $39.3 \%$ of them were studying in grade 12 and $57.4 \%$ were the first child.
The economic status of $72.7 \%$ of the subjects was at an average level and most of them $(80.2 \%)$ did not have any underlying diseases. Besides, $66.6 \%$ possessed private houses, and they were mostly $(92.6 \%)$ living with both parents. The educational level of $31.7 \%$ of the subjects' fathers and $39.6 \%$ of their mothers was a diploma. Furthermore, $43.4 \%$ of the fathers were self-employed, and $65.9 \%$ of the mothers were housewives. The Mean \pm SD score of the students' awareness was $8.52 \pm 3.18$, slightly larger than the median (7) of the instrument (Table 1).

The Mean \pm SD score of health-promoting lifestyle was $140 \pm 26.66$, being larger than the median. The students received a maximum mean score in the spiritual growth and self-actualization dimension (68.2) and a minimum mean score in the physical activity dimension of HPLP(II) (48.81) (Table 2). Only the health responsibility dimension of the health-promoting lifestyle was positively correlated with awareness. Put differently, with an increase in awareness, health responsibility ascended, as well (Table 3 ).

There was merely a statistically significant correlation between awareness of NAFLD and the educational

Table 1. Frequency distribution of awareness of non-alcoholic fatty liver among the students

\begin{tabular}{|c|c|c|c|c|}
\hline \multirow{2}{*}{\multicolumn{2}{|c|}{ Awareness }} & \multicolumn{3}{|c|}{ No. (\%) } \\
\hline & & Yes & No & I Do Not Know \\
\hline \multirow{2}{*}{$\begin{array}{l}\text { 1. In your opinion, } \\
\text { which one of the } \\
\text { below cases can lead } \\
\text { to cirrhosis? }\end{array}$} & Hepatitis A \& B infections & $58(17.2)$ & $21(6.2)$ & $259(76.6)$ \\
\hline & Fatty liver & $149(44.1)$ & $16(4.7)$ & $173(51.2)$ \\
\hline \multirow{4}{*}{$\begin{array}{l}\text { 2. In your opinion, } \\
\text { which one of these } \\
\text { conditions can lead } \\
\text { to a fatty liver? }\end{array}$} & Obesity & $279(82.5)$ & $7(2.1)$ & $52(15.4)$ \\
\hline & Diabetes & $116(34.3)$ & $62(18.3)$ & $160(47.3)$ \\
\hline & High cholesterol & $230(68.0)$ & $17(5.0)$ & $91(26.9)$ \\
\hline & Physical inactivity & $249(73.7)$ & $11(3.3)$ & $78(23.1)$ \\
\hline \multicolumn{2}{|c|}{ 3. Fatty liver is inherited. } & $96(28.4)$ & $227(67.2)$ & $15(4.4)$ \\
\hline \multicolumn{2}{|c|}{ 4. Is fatty liver treatable? } & $237(70.1)$ & $12(3.6)$ & $89(26.3)$ \\
\hline \multicolumn{2}{|c|}{ 5. Fatty liver is preventable. } & $319(94.4)$ & $7(2.1)$ & $12(3.6)$ \\
\hline \multicolumn{2}{|c|}{ 6. Is fatty liver treatable in the initial stages? } & $262(77.5)$ & $5(1.5)$ & $71(21.0)$ \\
\hline \multirow{3}{*}{$\begin{array}{l}\text { 7. How do doctors } \\
\text { diagnose a fatty liver? }\end{array}$} & Liver sonography & $157(46.4)$ & $23(6.8)$ & $158(46.7)$ \\
\hline & Blood test & $222(65.7)$ & $19(5.6)$ & $97(28.7)$ \\
\hline & Obesity & $106(31.4)$ & $59(17.5)$ & $173(51.2)$ \\
\hline \multicolumn{2}{|c|}{$\begin{array}{l}\text { 8. Do you think the fat in the liver can create a serious } \\
\text { health problem? }\end{array}$} & 294(87.0) & $5(1.5)$ & $39(11.5)$ \\
\hline \multicolumn{2}{|c|}{$\begin{array}{l}\text { Total score, mean } \pm S D \\
\text { Minimum-Maximum }\end{array}$} & & $\begin{array}{c}52.18 \pm 8.3 \\
0-14\end{array}$ & \\
\hline
\end{tabular}


Table 2. Mean score of the students' health-promoting lifestyle and its dimensions

\begin{tabular}{|c|c|c|c|c|c|c|}
\hline \multirow{2}{*}{$\begin{array}{l}\text { Health Promoting } \\
\text { Lifestyle \& its Dimen- } \\
\text { sions }\end{array}$} & \multirow{2}{*}{ Minimum } & \multirow{2}{*}{ Maximum } & \multirow{2}{*}{ Mean \pm SD } & \multicolumn{3}{|c|}{ 0-100 Basis } \\
\hline & & & & Minimum & Maximum & Mean $\pm S D$ \\
\hline $\begin{array}{l}\text { Spiritual growth and } \\
\text { self-actualization }\end{array}$ & 9 & 36 & $27.41 \pm 5.53$ & 0 & 100 & $68.2 \pm 20.49$ \\
\hline Health responsibility & 9 & 36 & $23.31 \pm 6.58$ & 0 & 100 & $53.03 \pm 24.38$ \\
\hline Interpersonal relations & 9 & 36 & $26.62 \pm 5.29$ & 0 & 100 & $65.27 \pm 19.61$ \\
\hline Stress management & 8 & 32 & $20.04 \pm 4.98$ & 0 & 100 & $50.2 \pm 20.77$ \\
\hline Physical activity & 8 & 32 & $19.71 \pm 6.63$ & 0 & 100 & $48.81 \pm 27.66$ \\
\hline Nutrition & 9 & 36 & $23.99 \pm 5.37$ & 0 & 100 & $55.53 \pm 19.91$ \\
\hline $\begin{array}{l}\text { Total Health promoting } \\
\text { lifestyle }\end{array}$ & 52 & 208 & $140.93 \pm 26.66$ & 0 & 100 & $57.01 \pm 17.09$ \\
\hline
\end{tabular}

Client- Centered Nursing Care

level of the subjects' fathers $(\mathrm{P}=0.004)$, such that the pairwise Tukey comparison indicated that the acquired mean score of adolescents whose fathers' educational level was M.A. and above was significantly higher than their counterparts whose fathers' education was diploma $(\mathrm{P}=0.002)$; however, this difference was not significant at other levels (Table 4).

The health-promoting lifestyle of the students was significantly related to their grades $(\mathrm{P}<0.001)$, such that the pairwise Tukey comparison revealed that the acquired mean score of grade 12 adolescents was significantly lower than their grade 10 counterparts $(\mathrm{P}<0.001)$. However, this difference was not significant at other levels. The birth order had also a statistically significant relationship with health-promoting lifestyle $(\mathrm{P}=0.019)$, such that the average score of students who were the third child in the family was significantly lower than the first children.
Likewise, the mean score of the health-promoting lifestyle of the students living with both parents was significantly higher than those living with one of their parents $(\mathrm{P}=0.031)$. Finally, age was also significantly correlated with health-promoting lifestyle; i.e., health-promoting lifestyle declined with aging $(\mathrm{P}=0.014)$ (Table 5).

\section{Discussion}

This study investigated the relationship between awareness of NAFLD and health-promoting lifestyle among adolescents in senior high schools in the west of Tehran in 2020. The mean awareness of the subjects was higher than the median. Gupta et al. (2019) in their study in India declared that people possess insufficient knowledge and extensively inadequate awareness of this disease (Gupta et al. 2019), the result that is incongruent with the findings of the current study. The reason for this can be

Table 3. Correlation between the students' health-promoting lifestyle and their awareness of the non-alcoholic fatty liver disease

\begin{tabular}{ccc}
\hline Health-Promoting Lifestyle and its Dimensions & of NAFLD \\
\cline { 2 - 2 } Spiritual growth and self-actualization & 0.06 \\
Health responsibility & 0.156 \\
Interpersonal relations & 0.047 \\
Stress management & 0.006 \\
Physical activity & 0.387 \\
Nutrition & 0.058 \\
Total health-promoting lifestyle & 0.287 \\
0.082 & 0.095 \\
\hline
\end{tabular}

Client- Centered Nursing Care 
Table 4. Relationship between the students' characteristics and their awareness of the non-alcoholic fatty liver disease

\begin{tabular}{|c|c|c|c|c|c|}
\hline \multicolumn{2}{|c|}{ Personal Characteristics } & \multirow{2}{*}{$\begin{array}{c}\text { Frequency } \\
156\end{array}$} & \multirow{2}{*}{$\begin{array}{c}\begin{array}{c}\text { Awareness, } \\
\text { Mean } \pm \text { SD }\end{array} \\
8.83 \pm 3.12\end{array}$} & \multirow{3}{*}{$\begin{array}{c}\text { Test Result } \\
t=1.626 \\
d f=336 \\
P=0.105\end{array}$} & \multirow{3}{*}{$\begin{array}{c}\text { Test Type } \\
\text { Independent t-test }\end{array}$} \\
\hline Gendor & Female & & & & \\
\hline Gerluer & Male & 182 & $8.26 \pm 3.22$ & & \\
\hline \multirow{3}{*}{ Grade } & 10 & 120 & $8.41 \pm 3.52$ & \multirow{3}{*}{$\begin{array}{l}F=0.349 \\
P=0.705\end{array}$} & \multirow{3}{*}{ ANOVA } \\
\hline & 11 & 85 & $8.77 \pm 2.91$ & & \\
\hline & 12 & 133 & $8.47 \pm 3.05$ & & \\
\hline \multirow{4}{*}{$\begin{array}{l}\text { Father's } \\
\text { educational } \\
\text { level }\end{array}$} & Below diploma & 34 & $8.23 \pm 2.9$ & \multirow{4}{*}{$\begin{array}{l}F=4.58 \\
P=0.004\end{array}$} & \multirow{4}{*}{ ANOVA } \\
\hline & Diploma & 106 & $7.7 \pm 3.36$ & & \\
\hline & B.A. & 105 & $8.77 \pm 2.98$ & & \\
\hline & M.A. \& above & 89 & $9.31 \pm 3.12$ & & \\
\hline \multirow{4}{*}{$\begin{array}{l}\text { Mother's } \\
\text { educational } \\
\text { level }\end{array}$} & Below diploma & 30 & $80.3 \pm 2.61$ & \multirow{4}{*}{$\begin{array}{c}F=0.419 \\
P=0.74\end{array}$} & \multirow{4}{*}{ ANOVA } \\
\hline & Diploma & 133 & $8.52 \pm 3.35$ & & \\
\hline & B.A. & 124 & $8.72 \pm 3.11$ & & \\
\hline & M.A. \& above & 49 & $8.41 \pm 3.31$ & & \\
\hline \multirow{3}{*}{$\begin{array}{c}\text { Father's } \\
\text { employment }\end{array}$} & Self-employed & 144 & $8.25 \pm 3.11$ & \multirow{3}{*}{$\begin{array}{l}F=0.967 \\
P=0.381\end{array}$} & \multirow{3}{*}{ ANOVA } \\
\hline & Employee & 139 & $8.71 \pm 3.22$ & & \\
\hline & Retired & 46 & $8.82 \pm 3.13$ & & \\
\hline \multirow{4}{*}{$\begin{array}{l}\text { Mother's em- } \\
\text { ployment }\end{array}$} & Housewife & 222 & $80.52 \pm 3.17$ & \multirow{4}{*}{$\begin{array}{l}F=0.304 \\
P=0.822\end{array}$} & \multirow{4}{*}{ ANOVA } \\
\hline & Self-employed & 24 & $8.79 \pm 3.64$ & & \\
\hline & Employee & 79 & $8.39 \pm 3.16$ & & \\
\hline & Retired & 12 & $9.25 \pm 2.8$ & & \\
\hline \multirow{3}{*}{ Birth order } & First & 194 & $8.44 \pm 3.22$ & \multirow{3}{*}{$\begin{array}{l}F=0.325 \\
P=0.723\end{array}$} & \multirow{3}{*}{ ANOVA } \\
\hline & Second & 110 & $8.72 \pm 3.05$ & & \\
\hline & Third and above & 34 & $8.35 \pm 3.44$ & & \\
\hline \multirow{3}{*}{$\begin{array}{l}\text { Economic } \\
\text { status }\end{array}$} & Weak & 14 & $8.42 \pm 4.81$ & \multirow{3}{*}{$\begin{array}{l}F=1.037 \\
P=0.356\end{array}$} & \multirow{3}{*}{ ANOVA } \\
\hline & Average & 246 & $8.37 \pm 3.16$ & & \\
\hline & Good & 78 & $8.97 \pm 2.88$ & & \\
\hline \multirow{3}{*}{ No. of children } & 1 & 141 & $8.38 \pm 3.34$ & & \\
\hline & 2 & 141 & $8.75 \pm 2.97$ & $\begin{array}{c}F=0.6232 \\
P=0.532\end{array}$ & ANOVA \\
\hline & $\geq 3$ & 56 & $8.32 \pm 3.33$ & & \\
\hline Underlying & No & 271 & $8.41 \pm 3.15$ & $\mathrm{t}=1.351$ & Indenendentt+t \\
\hline disease & Yes & 67 & $9.0 \pm 3.3$ & $P=0.178$ & \\
\hline & Rental & 106 & $8.19 \pm 3.43$ & & \\
\hline $\begin{array}{l}\text { Residence } \\
\text { conditions }\end{array}$ & Private & 223 & $8.72 \pm 3.05$ & $\begin{array}{l}F=1.153 \\
P=0.317\end{array}$ & ANOVA \\
\hline & Government-leased & 6 & $7.83 \pm 2.04$ & & \\
\hline Who are you & Both parents & 312 & $8.49 \pm 3.19$ & $t=0.588$ & \\
\hline living with? & One parent & 25 & $8.88 \pm 3.16$ & $P=0.557$ & 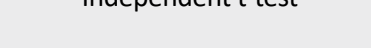 \\
\hline & Age & & $r=0.03 ; P=0.585$ & & Pearson correlation coefficient \\
\hline & BMI & & $r=0.094 ; P=0.084$ & & Pearson correlation coefficient \\
\hline
\end{tabular}


Table 5. Relationship between the students' characteristics and their health-promoting lifestyle

\begin{tabular}{|c|c|c|c|c|c|}
\hline \multicolumn{2}{|c|}{ Personal Characteristics } & \multirow{2}{*}{$\begin{array}{c}\text { Frequency } \\
156\end{array}$} & \multirow{2}{*}{$\begin{array}{c}\text { HPL, } \\
\text { Mean } \pm S D\end{array}$} & \multirow{3}{*}{$\begin{array}{c}\text { Test Result } \\
t=0.039 \\
d f=336 \\
P=0.969\end{array}$} & \multirow{3}{*}{$\begin{array}{c}\text { Test Type } \\
\text { Independent t-test }\end{array}$} \\
\hline Condor & Female & & & & \\
\hline Getrater a s & Male & 182 & $140.98 \pm 26.8$ & & \\
\hline \multirow{3}{*}{ Grade } & 10 & 120 & $147.7 \pm 26.97$ & \multirow{3}{*}{$\begin{array}{l}F=8.174 \\
P<0.001\end{array}$} & \multirow{3}{*}{ ANOVA } \\
\hline & 11 & 85 & $141.54 \pm 26.9$ & & \\
\hline & 12 & 133 & $134.43 \pm 24.78$ & & \\
\hline \multirow{4}{*}{$\begin{array}{l}\text { Father's educa- } \\
\text { tional level }\end{array}$} & Below diploma & 34 & $139.58 \pm 26.73$ & \multirow{4}{*}{$\begin{array}{l}F=0.517 \\
P=0.671\end{array}$} & \multirow{4}{*}{ ANOVA } \\
\hline & Diploma & 106 & $139.21 \pm 25.4$ & & \\
\hline & B.A. & 105 & $143.58 \pm 28.2$ & & \\
\hline & M.A. \& above & 89 & $141.37 \pm 28.2$ & & \\
\hline \multirow{4}{*}{$\begin{array}{l}\text { Mother's edu- } \\
\text { cational level }\end{array}$} & Below diploma & 30 & $138.87 \pm 25.41$ & \multirow{4}{*}{$\begin{array}{l}F=0.269 \\
P=0.848\end{array}$} & \multirow{4}{*}{ ANOVA } \\
\hline & Diploma & 133 & $142.27 \pm 28.87$ & & \\
\hline & B.A. & 124 & $140.97 \pm 23.92$ & & \\
\hline & M.A. \& above & 49 & $138.83 \pm 28.51$ & & \\
\hline \multirow{3}{*}{$\begin{array}{l}\text { Father's em- } \\
\text { ployment }\end{array}$} & Self-employed & 144 & $144.4 \pm 26.83$ & \multirow{3}{*}{$\begin{array}{l}F=1.282 \\
P=0.279\end{array}$} & \multirow{3}{*}{ ANOVA } \\
\hline & Employee & 139 & $140.12 \pm 26.56$ & & \\
\hline & Retired & 46 & $138.62 \pm 22.64$ & & \\
\hline \multirow{4}{*}{$\begin{array}{l}\text { Mother's em- } \\
\text { ployment }\end{array}$} & Housewife & 222 & $141.6 \pm 26.87$ & \multirow{4}{*}{$\begin{array}{l}F=0.471 \\
P=0.703\end{array}$} & \multirow{4}{*}{ ANOVA } \\
\hline & Self-employed & 24 & $134.8 \pm 23.8$ & & \\
\hline & Employee & 79 & $141.6 \pm 26.87$ & & \\
\hline & Retired & 12 & $140.74 \pm 24.82$ & & \\
\hline \multirow{3}{*}{ Birth order } & First & 194 & $143.14 \pm 27.39$ & \multirow{3}{*}{$\begin{array}{l}F=4.008 \\
P=0.019\end{array}$} & \multirow{3}{*}{ ANOVA } \\
\hline & Second & 110 & $140.65 \pm 24.6$ & & \\
\hline & Third and above & 34 & $129.24 \pm 26.54$ & & \\
\hline \multirow{3}{*}{ Economic status } & Weak & 14 & $121.91 \pm 31.05$ & \multirow{3}{*}{$\begin{array}{l}F=8.519 \\
P<0.001\end{array}$} & \multirow{3}{*}{ ANOVA } \\
\hline & Average & 246 & $139.14 \pm 24.74$ & & \\
\hline & Good & 78 & $149.5 \pm 29.0$ & & \\
\hline \multirow{3}{*}{ No. of children } & 1 & 141 & $144.31 \pm 24.5$ & & \\
\hline & 2 & 141 & $140.46 \pm 26.78$ & $\begin{array}{l}F=3.322 \\
P=0.037\end{array}$ & ANOVA \\
\hline & $\geq 3$ & 56 & $133.59 \pm 30.29$ & & \\
\hline Underlying & Not have & 271 & $142.14 \pm 26.41$ & $\begin{array}{l}t=1.686 \\
d f=336\end{array}$ & Indenendent t-test \\
\hline disease & Have & 67 & $136.02 \pm 27.33$ & $P=0.093$ & \\
\hline & Rental & 106 & $137.35 \pm 28.17$ & & \\
\hline $\begin{array}{l}\text { Residence } \\
\text { conditions }\end{array}$ & Private & 223 & $142.64 \pm 25.58$ & $\begin{array}{l}F=2.205 \\
P=0.112\end{array}$ & ANOVA \\
\hline & Government-leased & 6 & $7.83 \pm 2.4$ & & \\
\hline Who are you & Both parents & 312 & $141.79 \pm 26.82$ & $t=2.163$ & \\
\hline living with? & One parent & 25 & $129.85 \pm 22.83$ & $P=0.031$ & 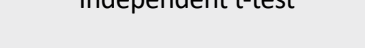 \\
\hline & Age & & $r=0.134$ & 014 & Pearson correlation coefficient \\
\hline & $\mathrm{BMI}$ & & $r=0.015$; & 786 & Pearson correlation coefficient \\
\hline
\end{tabular}


the impact of public media, especially television. Public media play a role in raising public awareness (Awad \& Al-Nafisi 2014). In their study, the subjects were general public with different levels of education, but in the present study, the subjects were adolescents with the widespread use of mass media and the Internet.

The results of the present study revealed that the mean score of health-promoting lifestyle was higher than the median. Among the scale dimensions, spiritual growth and self-actualization had the highest mean score, while the lowest mean score belonged to the physical activity dimension; after spiritual growth and self-actualization, interpersonal relations, nutrition, health responsibility, stress management, and physical activity were in the subsequent ranks.

Numerous studies have shown that their subjects in different groups enjoyed an acceptable and average status in terms of health-promoting lifestyle (Farahaninia et al. 2019); the results are congruent with the findings of the current study. However, the mean scores of the health-promoting lifestyle in other studies were below the median (Motaghi, Afsar \& Tavakoli 2015; Saadati \& Ghoreishi 2016; Siboni, Khatooni \& Atashi 2018).

The adolescents acquired the highest mean score in the spiritual growth and self-actualization dimension of health-promoting lifestyle. In the studies by Mohammad Alizadeh et al. (2013) among male adolescents, Kamali et al. (2016) among healthcare providers, and Rezaei et al. (2018) among students, the highest score belonged to the spiritual growth and self-actualization dimension, which is in line with the findings of the present study. However, in a study by Saadati et al. (2019), the nutrition dimension received the highest score. In the studies by Wei et al. (2012) and Danaei, Benam and Momeni (2018), the highest score belonged to the dimension of interpersonal relations. In the study by Molaeifard, Mohamadian and Haghighi Zadeh (2018) among high school students, the health responsibility dimension received the highest score.

The subjects of the current study acquired the lowest score in the physical activity dimension. This result is in line with the findings of some other studies (Ay et al. 2012; Balali Meybodi, Hasani \& Mehdinejad 2017). However, in some other studies, the lowest score was related to the health responsibility dimension (Mohammad Alizadeh et al. 2013; Raiyat et al. 2012; Wei et al. 2012), the result that was incongruent with the findings of the current study.
The low score on physical activity is probably due to the fact that teens spend most of their time on hobbies, such as using cell phones, tablets, computers, and playing computer games; therefore, they spend less time on exercise and physical activity, and ultimately, their health. (Tavafian \& Aghamolaei 2013).

There was a significant and positive relationship between awareness of NAFLD and the health responsibility subscale of health-promoting lifestyle, so that an increase in awareness, enhances responsibility, as well. In their study, Molaeifard, Mohamadian and Haghighi Zadeh (2018) stated that the constructs of the Information, Motivation, and Behavioral (IMB) skills model, directly and indirectly, affect the health-promoting lifestyle of students. Ammouri et al. (2018) showed that there was a positive relationship between awareness of risk factors of coronary artery disease and health-promoting behaviors. Saadati et al. (2019) also showed that health responsibility was the most effective factor in predicting the self-care behaviors of patients with heart failure.

The present study results showed that awareness of NAFLD was significantly related just to the educational level of the adolescents' fathers so that the awareness of adolescents whose fathers' educational level was M.A. and above was higher than the adolescents whose fathers had a diploma. Salehi and Farrokhian (2020) reported that there was a significant relationship between the students' mean scores of behavior, skills, and awareness and their parents' educational level and the highest mean score belonged to those whose parents' educational level was M.A. and Ph.D. and the lowest mean score was assigned to the students whose parents were illiterate or had a primary school degree. However, Mehdi Karami et al. (2019) revealed that the educational level of the high school students' fathers did not significantly affect the students' awareness, knowledge, attitude, and behavior regarding natural resources.

We found that the health-promoting lifestyle was significantly associated with the adolescents' grades so that the acquired mean score of adolescents in grade 12 was significantly lower than their counterparts in grade 10. Balali Meybodi et al. (2017) showed that the mean score of the health-promoting lifestyle of the students had a significant relationship with different educational levels. Nutritional behaviors, physical activity, interpersonal relationships, and spiritual growth of the students in the first grade were significantly higher than those in other grades. Mohammad Alizadeh et al. (2013) also introduced educational grade as an effective factor in the health-promoting lifestyle of male high school students. 
In contrast to our results, Chang (2011) in his study on Taiwanese adolescents stated that an increase in the educational level enhanced the probability of the subjects' health-promoting behaviors. By examining the predictors of health-promoting behaviors among Mexican students, Ulla Dies and Perez-Fortis (2010) explained that the mean score of health-promoting lifestyle enhanced when the educational level heightened.

Lack of time and lack of opportunities in upper-grade students can be one of the effective factors in inactivity because students in higher grades have to be prepared for university; thus, they focus on studying and pay less attention to health-promoting behaviors (Balali Meybodi, Hasani \& Mehdinejad 2017).

Our results showed that the students' health-promoting lifestyle was also related to the number of children, birth order, economic status, and living with parents. No study was found regarding the relationship between health-promoting lifestyle and number of children and birth order.

The mean score of health-promoting lifestyle in adolescents living with their parents was significantly higher than that of those living just with their father or mother. Tol et al. (2018) showed that living with the family and having a good economic status are positively related to a health-promoting lifestyle. With increasing income, health-promoting behaviors also increase. Other studies have also found a positive relationship between healthpromoting lifestyle and economic status (Wei et al. 2012; Siboni, Khatooni, \& Atashi 2018). Yarian and Ameri (2019) confirmed that people who have high social and economic status have a healthier life, smoke less, have a better diet and more physical activity, and take more care of their physical and mental health. They are doing health tests and have strong social relationships.

Our results showed that there was also a statistically negative and significant relationship between age and health-promoting lifestyle. In their study, Torabi et al. (2016) investigated the effective factors in adolescents' adoption of health-promoting behaviors using the Theory of Planned Behavior (TPB). They argued that the quality of students' lifestyles declined as they became older. Molaeifard, Mohamadian and Haghighi Zadeh (2018) also reported a significant reverse relationship between age and responsibility; i.e., younger individuals were more responsible for their health. Mohammad Alizadeh et al. (2013) and Rezaei et al. (2018) disclosed a significant relationship between age and health-promoting lifestyle.

\section{Conclusion}

The NAFLD has been recently become a social health problem and has attracted specific attention. The significant relationship between awareness of NAFLD and health responsibility reveals the importance of improving health-promoting lifestyles; therefore, it is suggested that planners, health service providers, nurses, and social media take a step towards providing educational interventions at different levels of prevention to empower adolescents to become responsible for their health and adopt a healthy lifestyle and with emphasis on controlling weight and increasing physical activity, be able to prevent chronic diseases, especially NAFLD.

\section{Ethical Considerations}

\section{Compliance with ethical guidelines}

The Ethics Committee of Iran University of Medical Sciences approved the study (Code: IR.IUMS. REC.1399.750). Due to the limitations caused by COVID-19, the researchers asked the school authorities to take the consent of the students and their parents and assure them about the confidentiality of the information.

\section{Funding}

The present article was extracted from the MSc. thesis of the first author in the Department of Community Health Nursing, School of Nursing and Midwifery, Iran University of Medical Sciences (IUMS) and was financially supported by the Vice-Chancellor for Research of IUMS.

\section{Authors' contributions}

Conceptualization: Farahnaz Barmak, Marhamat Farahaninia; Methodology: Farahnaz Barmak Marhamat Farahaninia and Hamid Haghani; Investigation: Farahnaz Barmak; Writing an original draft, writing, review, and editing: Farahnaz Barmak, Marhamat Farahaninia, Mehri Bozorgnejad; Supervision: Marhamat Farahaninia.

\section{Conflict of interest}

The authors declared no conflict of interest.

\section{Acknowledgments}

The authors appreciate the Faculty of Nursing and Midwifery and the Vice-Chancellor for Research of Iran University of Medical Sciences for the financial support. High school principals and officials of Shahid Motahari (Mr. Kamali) Narjes (MS. Ali Babaei), Mobasher, Mo- 
hajer -Irvani, Tazkieh, Iraj Rostami, Hazrat Zahra, Vahdat Islami, and Shahid Amouian schools are appreciated.

\section{References}

Alavian, M., 2012. [Comprehensive guideline fatty liver (Persian)] Tehran: Kowsar Health Researchers Cooperative Company. http://opac.nlai.ir/opac-prod/bibliographic/3041082

Allen, A. M., et al. 2018. Healthcare cost and utilization in nonalcoholic fatty liver disease: Real-world data from a large U.S. claims database. Hepatology, 68(6), pp. 2230-8. [DOI:10.1002/hep.30094] [PMID] [PMCID]

Ammouri, A. A., et al. 2018. Risk knowledge and awarness of coronary heart disease, and health promotion behaviors among adults in Oman. Research and Theory for Nursing Practice, 32(1), pp. 46-62. [DOI:10.1891/1541-6577.32.1.46] [PMID]

Anderson, E. L., et al. 2015. The prevalence of non-alcoholic fatty liver disease in children and adolescents: A systematic review and meta-analysis. PLoS One, 10(10), p. e0140908. [DOI:10.1371/ journal.pone.0140908] [PMID] [PMCID]

Awad, A. \& Al-Nafisi, H., 2014. Public knowledge of cardiovascular disease and its risk factors in Kuwaite: A cross-sectional survey. BMC Public Health, 14(1), pp. 1131-41. [DOI:10.1186/14712458-14-1131] [PMID] [PMCID]

Balali Meybodi, F., Hasani, M. \& Mehdinejad, M., 2017. [Evaluating health-promoting life style and its related factors among adolescent girls of Kerman in 2015 (Persian)]. Health \& Development Journal, 6(2), pp. 85-95. http://jhad.kmu.ac.ir/article_91247.html

Baum, F. \& Fisher, M., 2014. Why behavioural health promotion endures despite its failure to reduce health inequities. Sociology of Health \& Illness, 36(2), pp. 213-25. [DOI:10.1111/1467-9566.12112] [PMID]

Chalasani, N., et al. 2018. The diagnosis and management of nonalcoholic fatty liver disease: Practice guidance from the American Association for the study of liver diseases. Hepatology, 67(1), pp. 328-57. [DOI:10.1002/hep.29367] [PMID]

Chang, L. C., 2011. Health literacy, self-reported status and health promoting behaviours for adolescents in Taiwan. Journal of Clinical Nursing, 20(1-2), pp. 190-6. [DOI:10.1111/j.13652702.2009.03181.x] [PMID]

Chuang, S. P., et al. 2016. Self-concepts, health locus of control and cognitive functioning associated with health-promoting lifestyles in schizophrenia. Comprehensive Psychiatry, 70, pp. 82-9. [DOI:10.1016/j.comppsych.2016.06.014] [PMID]

Danaei, M., Benam, G. H. \& Momeni, M., 2018. [Health-promoting lifestyle among students in Kerman University of Medical Sciences, 2016 (Persian)]. Journal of Mazandaran University of Medical Science, 28(161), pp. 54-65. http://jmums.mazums.ac.ir/article1-10792-en.html

Farahaninia, M., et al. 2019. The relationship between knowledge about coronary heart diseases risk factors and health-promoting lifesyle. Journal of Client-Centered Nursing Care, 5(1), pp. 43-52. [DOI:10.32598/jccnc.5.1.43]
Ghevariya, V., et al. 2014. Knowing what's out there: Awareness of non-alcoholic fatty liver disease. Frontiers in Medicine, 1, p. 4. [DOI:10.3389/fmed.2014.00004] [PMID] [PMCID]

Gupta, M., et al. 2019. Investigational study on awareness of Non-Alcoholic Fatty Liver Disease (NAFLD) among people of Zirakpur (Punjsb) Region. Plant Archives, 19(2), pp. 1378-84. http:/ / www.plantarchives.org/SPL \%20ISSUE\%20SUPP\%20 2,2019/241\%20(1378-1384).pdf

Hallsworth, K., Avery, L. \& Trenell, M., 2016. Targeting lifestyle behavior change in adults with NAFLD during a 20-min consultation: Summary of the dietary and exercise literature. Current Gastroenterology Reports, 18(3), pp. 11-9. [DOI:10.1007/ s11894-016-0485-1] [PMID] [PMCID]

Kalroozi, F., et al. 2015. Health-promoting behaviors and related factors among nurse in selected military hospital. Military Caring Science, 1(2), pp. 73-80. [DOI:10.18869/acadpub.mcs.1.2.73]

Kamali, A. S. M. A., et al. 2016. Reliability and validity of Kurdish Language version of health promoting lifestyle profile ii among Kurdish healthcare providers Kurdish Version of HPLP-II. Archives of Iranian Medicine, 19(12), pp. 824-31. [PMID]

Kurnat-Thoma, E., et al. 2017. Nurses' health promoting lifestyle behaviors in a community hospital. Applied Nursing Research, 35(3), pp. 77-81. [DOI:10.1016/j.apnr.2017.02.012] [PMID]

Lankarani, K. B., et al. 2013. Non alcoholic fatty liver disease in southern Iran: A population based study. Hepatitis Monthly, 13(5), p. e9248. [DOI:10.5812/hepatmon.9248]

Mehdi Karami, S. H., et al. 2019. [Attitude of high school students to the importance and preservation of natural resources (Case Study: Khorramabad City, Iran) (Persian)]. Journal of Environment Science and Technology, 21(6), pp. 259-70. https:/ / jest.srbiau.ac.ir/article_12208.html?lang=en

Mohamadian, H., et al. 2013. [Psychometric properties of the Health-Promoting Lifestyle Profile (HPLP II) in a sample of Iranian adolescents (Persian)]. Payesh, 12(2), pp. 167-76. [DOI:2 0.1001.1.16807626.1392.12.2.5.6]

Mohammad Alizadeh Charandabi, S., et al. 2013. [Health promoting lifestyle and self-efficacy in male adolescents in Sanandaj (Persian)]. Journal of Mazandaran University of Medical Science, 23(109), pp. 152-62. http://jmums.mazums.ac.ir/ article-1-3386-en.html

Mohammadbeigi, A., et al. 2016. [Study of the relationship between self-efficacy and health-promoting lifestyle and associated factors in nurse (Persian)]. Qom University of Medical Science, 10(7), pp. 49-57. http://journal.muq.ac.ir/article1-433-en.html

Mohammadi Zeidi, I., Pakpuor Hajiagha, A. \& Mohammadi Zeidi, B., 2012. [Reliability and validity of Persian Version of the health-promoting lifestyle profile (Persian)]. Journal of Mazabdaran University of Medical Sciences, 21(1), pp. 102-13. http://jmums.mazums.ac.ir/article-1-955-en.html

Molaeifard, A., Mohamadian, H. \& Haghighi Zadeh, M. H., 2018. Evaluation of information-motivation-behavioral skills model in predicting health promoting lifestyle of high school students. Scientific Journal of School of Public Health and Institute of Public Health Research, 16(1), pp.19-32. [DOI:10.1515/ ijamh-2017-0194] [PMID] 
Motaghi, M., Afsar, M. \& Tavakoli, N., 2015. [Examination of the relationship between health-promoting behaviors and family characteristics in high school girl students (Persian)]. Nursing and Midwifery Journal, 13(5), pp. 395-403. http://unmf.umsu. ac.ir/article-1-2150-en.html

Neuschwander-Tetri, B. A., 2017. Non-alcoholic fatty liver disease. BMC Medicine, 15(1), p. 45. [DOI:10.1186/s12916-0170806-8] [PMID] [PMCID]

Paknahad, Z. \& Zeraei-Bidgoli, H., 2013. [Metabolic syndrome and nonalcoholic fatty liver disease: Nutritional approach for prevention (Persian)]. Journal of Isfahan Medical School, 31(252), pp. 1461-80. http://jims.mui.ac.ir/index.php/jims/article/ view/2611

Pender, N. J., Murdaugh, C. L. \& Parsons, M. A., 2015. Health promotion in nursing practice. New Jersey: Julie Levin Alexander. https://www.google.com/books/edition/_/o_jHng EACAAJ?hl=en\&sa=X\&ved=2ahUKEwicz6_j64P0AhVDzIUKHUZCCi8Qre8FegQIAxAi

Perdomo, C. M., Frühbeck, G. \& Perdomo, J., 2019. Impact of nutritional changes on nonalcoholic fatty liver disease. Nutrients, 11(3), p. 677. [DOI:10.3390/nu11030677] [PMID] [PMCID]

Raiyat, A., et al. 2012. [Health improving behaviors in students of Qazvin Secondary Schools in 2011 (Persian)]. Journal of Health Hygiene, 3(3), pp. 46-53. http://healthjournal.arums. ac.ir/article-1-65-en.html

Rezaei, Z., et al. 2018. [Study of the health-promoting lifestyle status of Students that Living in dormitories of Kurdistan University of Medical Sciences in 2016 (Persian)]. Rahavard Salamat Journal, 3(1), pp. 1-12. http://rsj.iums.ac.ir/article-1-61-en.html

Riegel, B., et al. 2018. Development and initial testing of the selfcare of chronic illness inventory. Journal of Advanced Nursing, 74(10), pp. 2465-76. [DOI:10.1111/jan.13775] [PMID]

Saadati, S., et al. 2019. Relationship between health-promoting lifestyle and self-care behaviors in patients with heart failure. Journal of Client-Centered Nursing Care, 5(1), pp.15-24. [DOI:10.32598/jccnc.5.1.15]

Saadati, M. \& Ghoreishi, Z., 2016. [Health promoting lifestyle in Shahed Students -Tabriz University of Medical Sciences (Persian)]. Depiction of Health, 7(1), pp. 27-33. https://doh.tbzmed. ac.ir/fa/Article/doh-145

Salehi, S. S. \& Farrokhian, F., 2020. [Evaluating environmental skill, behavior and awareness of primary school students (Persian)]. Journal of Environment Science and Technology, 22(7), pp. 127-37. https://jest.srbiau.ac.ir/article_16461.html?lang=en

Salehi Sahlabadi, A., et al. 2018. [The prevalence of nonalcoholic fatty liver disease in Iran adolescents: A systematic review and meta-analysis (Persian)]. Journal of Sabzevar University of Medical Sciences, 25(4), pp. 468-94. http:/ /jsums.medsab.ac.ir/ article_1094_en.html

Schnall, R., Okoniewski, A. \& Tiase, V., 2013. Using text messaging to assess adolescents' health information needs: Anecological momentary assessment. Journal of Medical Internet Research, 15(3), p. e54. [DOI:10.2196/jmir.2395] [PMID] [PMCID]

Ay, S., et al. 2012. Health-promoting lifestyle behaviour for cancer prevention: A survey of Turkish University Students. Asian Pacific Journal of Cancer Prevention, 13(5), pp. 2269-77. [DOI:10.7314/APJCP.2012.13.5.2269] [PMID]
Shaman, R., et al. 2017. Non-alcoholic fatty liver disease and its association among adolescents in an urban, Sri Lankan community. BMC Gastroenterology, 17(1), p. 135. [DOI:10.1186/ s12876-017-0677-7] [PMID] [PMCID]

Shen, H., et al. 2014. Association between nonalcoholic fatty liver disease and colorectal adenoma: A systemic review and metaanalysis. Journal of Gastrointestinal Oncology, 5(6), pp. 440-6. [DOI:10.3978/j.issn.2078-6891.2014.061] [PMID] [PMCID]

Siboni, F. S., Khatooni, M. \& Atashi, V., 2018. Health-promoting lifestyle practices among patients with chronic diseases and its related factors. Social Health Behavior, 1(2), pp. 67-73. [DOI:10.4103/SHB.SHB_29_18]

Tavafian, S. S. \& Aghamolaei, T., 2013. [Assessing lifestyle of high school students in Bandar Abbas, Iran (Persian)]. Journal of School of Public Health and Institute of Public Health Research, 11(3), pp. 83-93. http://sjsph.tums.ac.ir/article-1-5062-en. html

Tol, A., et al. 2018. [Influential factors on health promoting behaviors and happiness among women (Persian)]. Razi Journal of Medical Sciences, 25(169), pp. 12-22. http://rjms.iums.ac.ir/ article-1-5129-en.html

Torabi, F., et al. 2016. [Examining the influential factors in adopting lifestyle-promoting behaviors in adolescents using theory of planned behavior (Persian)]. The Journal of Toloo-e-behdasht, 14(6), pp. 79-93. http://tbj.ssu.ac.ir/article-1-1976-en.html

Tsuneto, A., et al. 2010. Fatty liver incidence and predictive variables. Hypertension Research, 33(6), pp. 638-43. [DOI:10.1038/ hr.2010.45] [PMID]

Ulla Díez, S. M. \& Pérez-Fortis, A., 2010. Sociodemographic predictors of health behaviors in Mexican college students. Health Promotion International, 25(1), pp. 85-93. [PMID]

Vos, M. B., et al. 2017. Clinical practice guideline for the diagnosis and treatment of nonalcoholic fatty liver disease in children: recommendations from the Expert Committee on NAFLD (ECON) and the North American Society of Pediatric Gastroenterology, Hepatology and Nutrition (NASPGHAN) Journal of Pediatric Gastroenterology and Nutrition, 64(2), pp. 31934. [DOI:10.1097/MPG.0000000000001482] [PMID] [PMCID]

Walker, S. N., Sechrist, K. R. \& Pender, N. J., 1987. The healthpromoting lifestyle profile: Development and psychometric characteristics. Nursing Research, 36(2), pp. 76-81. [DOI:10.1097/00006199-198703000-00002]

Wei, C. N., et al. 2012. Assessment of health-promoting lifestyle profile in Japanese university students. Environmental Health and Preventive Medicine, 17(4), pp. 222-7. [DOI:10.1007/s12199011-0244-8] [PMID] [PMCID]

Yarian, S. \& Ameri, N. F., 2019. [Explaining students' Islamic lifestyle and mental health based on the socio-economic status of the family (Persian)]. Journal of Islamic Lifestyle, 3(4), pp. 21-7. http://islamiclifej.com/article-1-339-en.html

Younossi, Z. M., 2019. Non-alcoholic fatty liver disease - a global public health perspective. Journal of Hepatology, 70(3), pp. 531-44. [DOI:10.1016/j.jhep.2018.10.033] [PMID]

Younossi, Z. M., et al. 2016. The economic and clinical burden of nonalcoholic fatty liver disease in the United States and Europe. Hepatology, 64(5), pp. 1577-86. [DOI:10.1002/hep.28785] [PMID] 
Zolfaghari, H., et al. 2016. Intake of nutrients, fiber, and sugar in patients with nonalcoholic fatty liver disease in comparison to healthy individuals. International Journal of Preventive Medicine, 7(98), pp. 1801-29. [DOI:10.4103/2008-7802.188083] [PMID] [PMCID]

Zou, T. T., et al. Lifestyle interventions for patients with nonalcoholic fatty liver disease: A network meta-analysis. European Journal of Gastroenterology \& Hepatology, 30(7), pp. 747-55. [DOI:10.1097/MEG.0000000000001135] [PMID] 